\title{
Contribution to the Detection of Poor Quality Sildenafil Drugs in Burkina Faso Using High-Performance Thin-Layer Chromatography
}

\author{
Abdoul Karim Sakira $(\mathbb{D}$, Mitéhélé Sandrine Marie Josiane Ouattara, Moussa Yabre $\mathbb{D}$, \\ Moumouni Bande, and Touridomon Issa Some \\ Laboratoire de Toxicologie, Environnement et Santé (LATES), Ecole Doctorale des Sciences de La Santé (ED2S), \\ Université Joseph KI-ZERBO, 03 BP 7021 03, Ouagadougou, Burkina Faso \\ Correspondence should be addressed to Abdoul Karim Sakira; akarimsak82@gmail.com
}

Received 23 July 2021; Revised 18 September 2021; Accepted 25 September 2021; Published 13 October 2021

Academic Editor: María José Trujillo-Rodríguez

Copyright (C) 2021 Abdoul Karim Sakira et al. This is an open access article distributed under the Creative Commons Attribution License, which permits unrestricted use, distribution, and reproduction in any medium, provided the original work is properly cited.

\begin{abstract}
In substandard drugs enforcement, there is a need to develop reliable, fast, and inexpensive analytical methods. Due to its very characteristics, HPTLC offers opportunities for the development of methods that meet these requirements. This technique was used to develop and validate a method for the determination of sildenafil in pharmaceutical formulations from the licit and illicit supply chain in Burkina Faso. Taking into account optimization parameters such as measurement wavelength and mobile phase composition, the best elution quality is found at the maximum signals of spots on silica plates at $305 \mathrm{~nm}$, using a mixture of dichloromethane-methanol mixture $9: 1(\mathrm{v} / \mathrm{v})$ proportions. The method developed under these conditions was validated using the accuracy profile as a decision tool. The establishment of the response function curves allowed the choice of the polynomial function applied to the peak areas. This mathematical model provides a validity range between 0.4 and $0.6 \mathrm{mg} / \mathrm{mL}$. The application of the developed and validated method to collected samples allowed the detection of two substandard drugs and confirmed the poor quality of drugs in the illicit market. More data using this approach in a variety of drug molecules could lead to the establishment of databases of counterfeit drugs in Burkina Faso.
\end{abstract}

\section{Introduction}

Data from the literature show that the market share of illicit or falsified drugs is estimated at $10 \%$ with an increasing trend in some countries. All therapeutic classes are concerned. These falsified drugs cover a range from products with unknown sources to those with or without active ingredient, under- or overdosed, or with falsified expiration date $[1-5]$.

Falsified or poor quality medicines are a serious concern to public health worldwide, especially for developing countries where surveillance systems are weak and quality control of drugs is inefficient. The quality control of medicines is generally based on the monographs of the different pharmacopoeias and particularly from WHO. Counterfeiting analysis can be done by simple visual inspection or through the use of sophisticated techniques including imaging, spectrometric, and chromatographic techniques. The analytical methods to be used are classified into two main groups: destructive methods and nondestructive methods; the latter can be performed outside the laboratory. Among the destructive methods are nuclear magnetic resonance (NMR), atomic absorption spectrophotometry, gas chromatography, and liquid chromatography coupled with diode array or mass spectrometer detector and thin-layer chromatography $[2,6]$. Nondestructive methods include X-ray diffraction, mid- and near-infrared spectrophotometry, and Raman spectrophotometry.

In drug counterfeiting enforcement, it is necessary to have simple, fast, and efficient methods for the analysis of suspect products, and High-Performance Thin-Layer Chromatography (HPTLC), by its very characteristics, offers 
an opportunity to achieve these objectives. This technique uses a simple and reliable apparatus, which does not require large quantities of solvents, is not time-consuming compared to HPLC, and minimizes the effect of the matrix on the analysis. Automation of deposition and quantification and improved quality of stationary phases combined with readyto-use analytical plates make HPTLC robust, fast, and sensitive which can be coupled with satisfactory sensitivity detectors such as the photodensitometer and mass detector [7-9]. As a result, HPTLC is gradually gaining acceptance in regulatory monographs and in particular for the analysis of natural extracts where matrices are often very complex $[7,10,11]$. In addition, due to its relatively affordable cost per analysis, it appears to be an excellent alternative adapted to the context of developing countries, to control the quality of various products, particularly pharmaceuticals. HPTLC has already been successfully implemented in these countries for the quality control of various pharmaceutical products such as antituberculosis, antibiotics, antifungals, and antiretroviral drugs $[12,13]$. In this study, we developed and validated a method for the analysis of pharmaceutical formulations of sildenafil from the licit and illicit distribution chain, using HPTLC. This molecule is a phosphodiesterase type 5 inhibitor, used in erectile dysfunction, which since its introduction has been frequently used in adulterations of herbal products and dietary supplements [14-16]. This study will contribute to generating data on the issue of counterfeiting in Burkina Faso.

\section{Materials and Methods}

2.1. Sampling. All the drugs analyzed were collected in the Central, Central-East, South-West, and South-Central regions of Burkina Faso. Samples from the licit supply chain were purchased in pharmacies and private pharmaceutical stores. Samples from the illicit market came from different places in the same regions. The characteristics of the samples collected are noted in Table 1.

2.2. Reagents and Standards. Reagents and analytical standards used for the implementation of the HPTLC method were as follows: methanol (HiPerSolv purity $\geq 99,8 \%$ ), dichloromethane (HiPerSolv purity $\geq 99,8 \%$ ), chloroform (HiPerSolv CHROMANORM, purity $\geq 99,8 \%$ ), acetone (HiPerSolv CHROMANORM) all from VWR; ammonium hydroxide solution (25\%) from Honeywell Fluka ${ }^{\mathrm{TM}}$ ); and diethylamine (purity $\geq 99.5 \%$ ) from Sigma-Aldrich.

Sildenafil citrate (purity $\geq 98 \%$ ) was from Sigma-Aldrich and Viagra ${ }^{\circledR}$ tablets $50 \mathrm{mg}$ B/4 B226423B from Pfizer limited. ERECTAD ${ }^{\circledR}$ (tadalafil tablets) $20 \mathrm{mg} \mathrm{B/4} \mathrm{AT2E-1601}$ was from ASMOH Laboratories Limited.

2.3. Instrumentation. A High-Performance Thin-Layer Chromatography line comprising of several modules was used. Automatic TLC Sampler 4 (CAMAG, Switzerland) was used for the application of the samples. Chromatographic development was done using a Twin trough chamber $(20 \times 10 \mathrm{~cm} ; 20 \times 20 \mathrm{~cm}$ Camag, Switzerland $)$. An UV chamber (Camag, Switzerland) made it possible to visualize the chromatographic plates (Merck TLC silica gel $\left.\mathrm{F}_{254} 20 \times 10 \mathrm{~cm}\right)$. The detection and the quantitative analysis of the strips were carried out using the photodensitometer TLC scanner 4 (Camag, Switzerland). The operating parameters have been set using the vision CATS ${ }^{\circledR} 2.4$ software.

\subsection{Preparation of Calibration and Validation Standard} Solutions. A stock solution of sildenafil citrate at $1.0 \mathrm{mg} / \mathrm{mL}$ was prepared by dissolving exactly $20 \mathrm{mg}$ of powder in $20 \mathrm{~mL}$ of methanol. The mixture was stirred in an ultrasonic bath (sonicator) for 20 minutes. Aliquots of the stock solutions were appropriately diluted with methanol to obtain working standards of $0.1 \mathrm{mg} / \mathrm{mL}, 0.3 \mathrm{mg} / \mathrm{mL}$, and $0.7 \mathrm{mg} / \mathrm{mL}$. The Viagra ${ }^{\circledR}$ sample used for the validation of the method on the matrix was prepared under the same conditions. It was diluted to the same concentrations as the daughter solutions of the standard's calibration, that is, approximately $0.1 \mathrm{mg} /$ $\mathrm{mL}, 0.3 \mathrm{mg} / \mathrm{mL}$, and $0.7 \mathrm{mg} / \mathrm{mL}$.

2.5. Sample Solutions Preparation. Depending on the packaging, at least three tablets per sample from the same batch were weighed and then crushed. A quantity of powder equivalent to approximately $10 \mathrm{mg}$ of sildenafil citrate was weighed and placed in a $10 \mathrm{~mL}$ volumetric flask. Approximately, $7 \mathrm{~mL}$ of methanol was added and the solution was vortexed for 5 minutes and then $20 \mathrm{~min}$ in the ultrasonic bath. The volume was completed with methanol just after. The concentration of the sample stock solution of sildenafil citrate was $1 \mathrm{mg} / \mathrm{mL}$. The resulting solution was filtered through a $0.45 \mu \mathrm{m}$ PTFE filter, and then $5 \mathrm{~mL}$ of the filtered solution was transferred in a $10 \mathrm{~mL}$ volumetric flask. The final concentration of the sample solution was $0.5 \mathrm{mg} / \mathrm{mL}$ of sildenafil. The obtained working solutions were conditioned in $1.5 \mathrm{~mL}$ vials.

2.6. Chromatographic Procedure: Optimization. The influence of several operational and instrumental parameters during the optimization of the method depending on the substance and the matrix can be analyzed in HPTLC. In the present study, the vertical mode plate development and the deposition of samples in strip form were retained. The influence of mobile phase composition and wavelength were tested. Three different mobile phases and six wavelengths used in previous HPTLC sildenafil assay studies were tested [17-19]. For the mobile phases, the following systems were used:

(i) Mobile phase 1: dichloromethane-acetone-hydroxide ammonium $(20: 1.5: 0.2, \mathrm{v} / \mathrm{v} / \mathrm{v})$ and $(10: 10$ : $0.2, \mathrm{v} / \mathrm{v} / \mathrm{v}$ )

(ii) Mobile phase 2: chloroform-diethylamine-metha$\operatorname{nol}(15: 3: 2, \mathrm{v} / \mathrm{v} / \mathrm{v})$

(iii) Mobile phase 3: dichloromethane-methanol (9:1, $\mathrm{v} / \mathrm{v})$

A wavelength range from $254 \mathrm{~nm}$ to $366 \mathrm{~nm}$ was tested and the wavelengths, namely, $254 \mathrm{~nm}, 278 \mathrm{~nm}, 292 \mathrm{~nm}$, 
TABLE 1: Characteristics of analyzed samples.

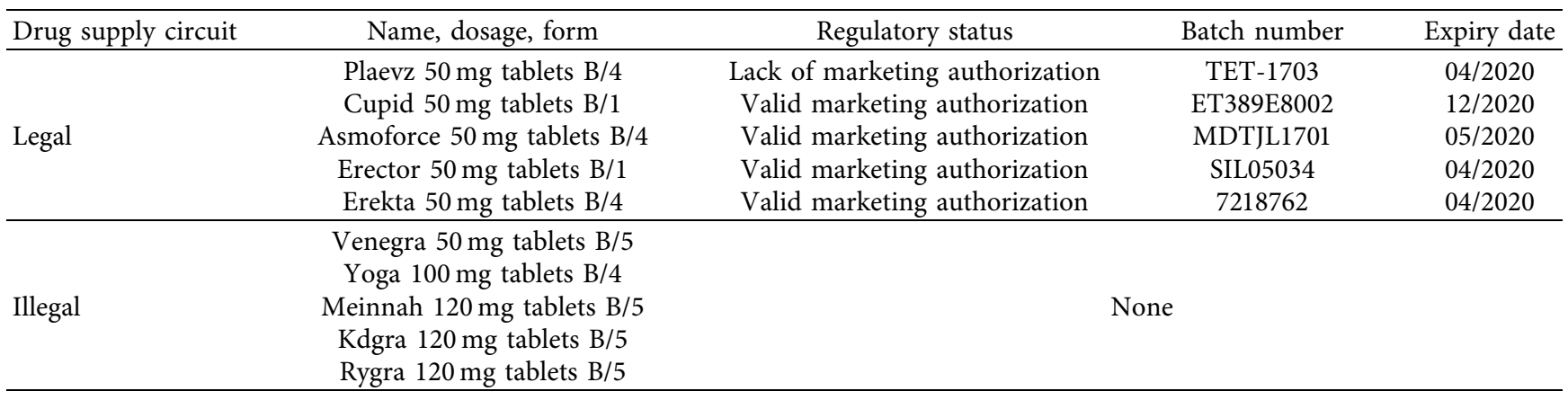

$305 \mathrm{~nm}, 312 \mathrm{~nm}$, and $333 \mathrm{~nm}$, were selected after optimization. The final selected operating conditions are summarized in Table 2.

\subsection{Identification and Sildenafil Quantification.} Densitometric scanning was performed using a Camag TLC Scanner 4, and the densitograms are generated by the visionCATS ${ }^{\circledR} 2.4$ software. The strip or spot readings are made at different wavelengths in absorption-reflection mode. The following scanning parameters were used: slit dimension $(5.00 \times 0.20 \mathrm{~mm}$, micro $)$, scanning speed $20 \mathrm{~mm} / \mathrm{s}$, and data resolution $100 \mu \mathrm{m} / \mathrm{step}$. The scanning was done between 190 and $900 \mathrm{~nm}$ range using deuterium and tungsten lamps.

The quantification is based on peak areas peak height. The concentrations are calculated based on the polynomial regression model using the standard concentrations versus reflected intensities. The identification of sildenafil is made by comparing the frontal reference (ratio) of the sildenafil standard and that of the analyzed sample. This frontal ratio corresponds to the migration distance of the substance over the solvent front.

2.8. Method Validation. The validation strategy is the accuracy profile, a graphical and visual decision tool for the validation of assay methods [20-22]. This validation strategy combines two fundamental elements of validation, namely, the accuracy and precision of the final measurement result. It, therefore, takes into account the total measurement error (systematic + random). Accuracy profile validation is based on the estimation of a range within which the result of a measurement lies and the verification that it is within the set limits. The principle is based on the statement that the difference between a measure $(x)$ and its true value $(\mu)$ must be less than the predefined acceptance limit $(\lambda)$ : $-\lambda<x-\mu<\lambda \Longleftrightarrow|x-\mu|<\lambda$.

2.8.1. Validation Criteria Used. The validation plan applied is summarized in Table 3 [23].

Specificity of the Method. The evaluation of this parameter was based on the discrimination of the sildenafil peak with those of other present or chemically similar substances such as tadalafil. This discrimination takes into account the evaluation of the purity of the peaks through their forms [24]. It was estimated by calculating the resolution parameter that takes into account the frontal ratios recorded on the chromatographic profiles.

Tolerance Interval and Accuracy. The proposed method would be validated if the different tolerance limits of the results remain within the acceptance limits in a given interval called the validity interval. The probability $\beta$ associated with the tolerance interval is $80 \%$ and the acceptance limits are $\pm 10 \%$ [25]. The accuracy profile was constructed based on the trueness and precision data.

Trueness. It is expressed in terms of bias $(\mathrm{mg} / \mathrm{ml})$, relative bias (\%), and recovery.

Precision. The precision was analyzed in terms of repeatability and intermediate precision. To provide an indication of errors due to chance, the precision was expressed in terms of standard deviation and coefficient of variation [26].

Data Processing. The data collected was processed using Excel version 2013. Two mathematical models were tested to define the calibration curve: the quadratic function $\left(y=a x^{2}+b x+c\right)$ and the logarithmic function $(y=a$ $\ln (x)+b)$.

After the establishment of calibration models and the estimation of the coefficients, the inverse predicted concentrations were calculated, as well as the precision and trueness of data. Tolerance intervals were calculated for accuracy profile plotting.

The equations used to calculate the different validation parameters are presented in Supplementary Materials (available here). The methods of calculation of the fidelity and trueness criteria are presented in Table 4 [23]. Table 5 summarizes formulas used to calculate various components of the accuracy profile, including tolerance interval limits per level [23].

\section{Results and Discussion}

\subsection{Method Optimization}

3.1.1. Mobile Phase Selection. During the mobile phase optimization, the dichloromethane-acetone-ammonium 
TABLE 2: Optimized operating conditions for the determination of sildenafil.

\begin{tabular}{lc}
\hline Parameters & Value/selected characteristic(s) \\
\hline Mobile phase & Methylene chloride-methanol $(9: 1, \mathrm{v} / \mathrm{v})$ \\
Solubilization and dilution solvent & Methanol \\
Plates & Merck TLC silica gel $\mathrm{F}_{254} 20 \times 10 \mathrm{~cm}$ \\
Deposited volume on the plate & $5 \mu \mathrm{L}$ \\
Width of the deposit strip & $7.4 \mathrm{~mm}$ \\
Length between deposits & $9.4 \mathrm{~mm}$ \\
Distance from the deposition line to the edges of the plate (abscissa and ordinate) & 8 and $10 \mathrm{~mm}$ \\
Development distance on plate & $70 \mathrm{~mm}$ \\
Development mode & Linear ascending mode \\
Saturation time of mobile phase & 30 min \\
Deposit flow & $15 \mu \mathrm{L} / \mathrm{s}$ \\
Deposit mode & Spray \\
Gas for sample application & Nitrogen \\
Detection wavelength & $305 \mathrm{~nm}$ \\
\hline
\end{tabular}

TABLE 3: Validation plan.

\begin{tabular}{lc}
\hline Parameters & Number of analysis \\
$\begin{array}{l}\text { Calibration plan (response function) } \\
\text { Validation plan (standard) }\end{array}$ & $\begin{array}{c}\text { Five (5) series realized in the conditions of intermediate fidelity } \\
\text { Four (4) levels of concentration } \\
\text { Three (3) repetitions per concentration level } \\
\text { Five (5) series carried out under the conditions of intermediate fidelity } \\
\text { Four (4) levels of concentration } \\
\text { Three (3) repetitions per concentration level } \\
\text { Validation plan (sample) }\end{array}$ \\
$\begin{array}{c}\text { Three (3) series carried out under the conditions of intermediate fidelity } \\
\text { Four (4) levels of concentration }\end{array}$ \\
Three (3) repetitions per concentration level
\end{tabular}

TABLE 4: Mode of calculation of the criteria of fidelity and trueness by level.

\begin{tabular}{lcc}
\hline Criteria & $\begin{array}{c}\text { Calculation } \\
\text { methods }\end{array}$ & $\begin{array}{c}\text { Levels } \\
\ldots \mathrm{k}\end{array}$ \\
\hline $\begin{array}{l}\text { Intermediate fidelity standard } \\
\text { deviation }\end{array}$ & $S_{k F I}=\sqrt{\left(S_{k r+}^{2} S_{k B}^{2}\right)}$ & \\
$\begin{array}{l}\text { Intermediate fidelity variation } \\
\text { coefficient }\end{array}$ & $\left(S_{k F I} / \overline{\bar{x}}_{k}\right) \times 100$ \\
Absolute mean bias & $\overline{\bar{z}}_{k}-\overline{\bar{x}}_{k}$ & \\
$\begin{array}{l}\text { Relative average bias } \\
\text { Average recovery rate }\end{array}$ & {$\left[\overline{\bar{z}}_{k}-\overline{\overline{\bar{x}}}_{k} / \overline{\bar{x}}_{k}\right] \times 100$} \\
& $\left(\overline{\bar{z}}_{k} / \overline{\bar{x}}_{k}\right) \times 100$ & \\
\hline
\end{tabular}

$\overline{\bar{z}}_{k}$ : mean concentration found; $\overline{\bar{x}}_{k}$ : mean reference value; $s_{k r}$ : repeatability standard deviation; $s_{k B}$ : interseries standard deviation.

TABle 5: Modes of calculation of accuracy profile parameters.

\begin{tabular}{lcc}
\hline Criteria & Calculation methods & \multicolumn{2}{c}{ Levels } \\
& $1 \quad \ldots \quad \mathrm{k}$ \\
\hline Low tolerance limit & $\overline{\bar{z}}-K_{\mathrm{tol}} \times s_{\mathrm{IT}}$ & \\
High tolerance limit & $\overline{\bar{z}}+K_{\mathrm{tol}} \times s_{\mathrm{IT}}$ & \\
Relative low tolerance limit & {$\left[\overline{\bar{z}}-k_{\mathrm{tol}} \times s_{\mathrm{IT}} / \overline{\bar{x}}\right] \times 100$} & \\
Relative high tolerance limit & {$\left[\overline{\bar{z}}+k_{\mathrm{tol}} \times s_{\mathrm{IT}} \overline{\bar{x}}\right] \times 100$} & \\
Low acceptability limit & $(-\lambda)$ \\
High acceptability limit & $(+\lambda)$ & \\
\hline
\end{tabular}

$s_{\mathrm{IT}}$ : standard deviation of the tolerance interval; $k_{\mathrm{tol}}$ : tolerance interval coverage factor. hydroxide system $(20: 1.5: 0.2, \mathrm{v} / \mathrm{v} / \mathrm{v})$ did not allow the elution of band-shaped deposits from the baseline after $30 \mathrm{~min}$ of plate development. With the second solvent system "dichloromethane-acetone-ammonium hydroxide" $(10: 10: 0.2, \mathrm{v} / \mathrm{v} / \mathrm{v})$, the migration was less than $2 \mathrm{~cm}$ from the deposition line, with an $R_{f}<0.2$. Therefore this mobile phase was not used in further developments. The use of chloroform-diethylamine- methanol system $(15: 3: 2, \mathrm{v} / \mathrm{v} / \mathrm{v})$, resulted in bands eluted to the solvent front.

The "dichloromethane and methanol" system in the ratio of $9: 1(\mathrm{v} / \mathrm{v})$ gave the best migration profile with a frontal ratio between 0.5 and 0.6 (Figure 1).

This is in line with the optimal performance of the composition of a mobile phase that should allow a frontal ratio between 0.2 and 0.8 [24]. The presence of any trace between the deposition line and the eluted band indicates that the substance has been fully eluted (Figure 1). The frontal ratio average is $0.595 \pm 0.015$ for sildenafil under these mobile phase conditions. In a similar analysis of sildenafil by HPTLC, the authors found a frontal ratio of $0.53 \pm 0.01$ with a chloroform-methanol-diethylamine (90: $10: 1, \mathrm{v} / \mathrm{v} / \mathrm{v})$ mobile phase [27].

3.1.2. Wavelength Selection. The areas under the curve obtained at the different wavelengths tested with solutions of different concentrations are shown in the supplementary material (Table 1, Supplementary material). The 


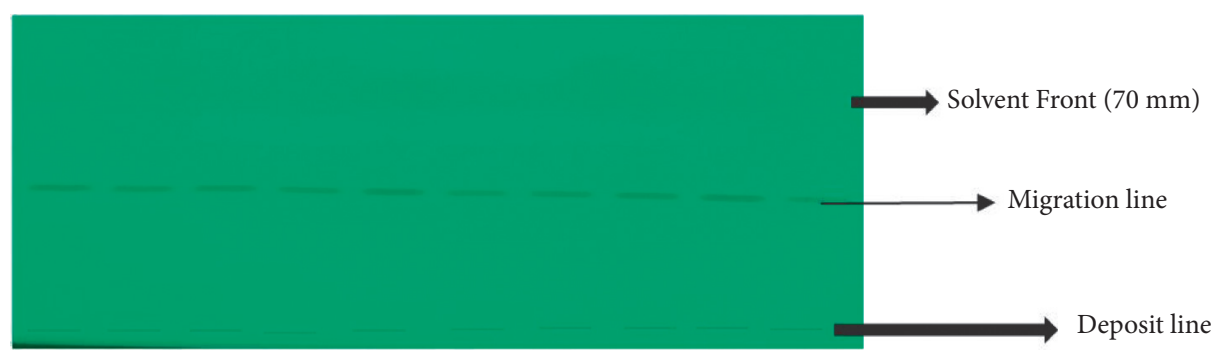

FIgURE 1: Chromatographic plate obtained with a mobile phase dichloromethane-methanol (9:1, v/v) and revealed at $254 \mathrm{~nm}$.

measurements on the same plate were repeated three times. At the wavelength of $305 \mathrm{~nm}$, the areas of the peaks were the largest. This wavelength was chosen for further measurements of peak areas and peak heights. This wavelength seems the best for sildenafil analysis as other authors found the same in their work on the determination of sildenafil by HPTLC in aphrodisiac plant preparations [27].

3.1.3. Assessment of Specificity. Specificity was assessed by comparing the peak profile and the frontal ratio of sildenafil citrate with that of tadalafil, another phosphodiesterase type 5 inhibitor. The frontal ratios are respectively estimated at $0.592 \pm 0.015$ for sildenafil citrate and $0.806 \pm 0.010$ for tadalafil are shown in Figures 2 and 3. There is very good discrimination between the peaks of the two compounds and this was confirmed by the estimated resolution of 2.77 (Equation (1), Supplementary material).

Good separation of compounds observed on the chromatographic plates as well as the chromatogram allowed identifying unequivocally each of the two substances according to their frontal ratios. The method was then specific in determining the mixture composition.

The chromatograms obtained with the deposition of sildenafil, tadalafil, and the solution containing both substances showed the Gaussian profile for all peaks. The frontal ratio of Sildenafil was 0.589 . The mean $R_{f}$ of sildenafil was $0.592 \pm 0.015$. This is in the range of 0.2 and 0.8 as required for HPTLC separation. The frontal ratio of tadalafil is 0.815 with a mean of $0.806 \pm 0.010$.

\subsection{Validation by Accuracy Profile}

3.2.1. Calibration Plan. The equations obtained for the response functions (calibration data) were made with the heights and the areas of the peaks on each of the five series. The mathematical models used and the equations of the calibration lines are presented in the supplementary material (Table 2, Supplementary material). The coefficients of determination $\left(R^{2}\right)$, close to 1 , allow saying that the variability of the heights and areas of the peaks can be explained by these mathematical models.

3.2.2. Linearity Profiles. The calculation of recovery lines is presented in Table 6. It was obtained using logarithmic and polynomial models.
The overlap lines related to equations (3) and (4) are those that best satisfy the linearity criteria according to ISO [28]. The slopes and coefficients of determination of these lines are close to 1 and their intercept is close to zero (0).

Therefore the logarithm function applied to the peak heights or the polynomial function applied to the areas could be used for the validation of the method. However, the linearity profile does not give guarantees that each future result will be close enough to the true value and that a systematic error could compensate a random error and vice versa.

3.2.3. Construction of the Accuracy Profile. The accuracy profile was constructed based on the fidelity and trueness data. These data were calculated using logarithmic and polynomial functions based on peak areas and peak heights. The best fit is the one built with the polynomial function applied to the peak areas (Figure 4).

The range of concentrations obtained is between 0.2 and $0.6 \mathrm{mg} / \mathrm{mL}$ with the tolerance limits included in the acceptance limits. When using the logarithmic function and the polynomial function applied to peak heights, the working concentration ranges lead to results that are outside the tolerance and acceptance limits and therefore cannot be used for further validation. Therefore, the quadratic function was selected as the mathematical calibration model. For the validation of the method in the matrix, the Viagra ${ }^{\circledR}$ sample was a reference matrix, and the polynomial function applied to the peak areas was used. It allowed the construction of an accuracy profile establishing the validity interval between 0.4 and $0.6 \mathrm{mg} / \mathrm{mL}$ (Figure 5). The performance metrics for fidelity and accuracy are summarized in Tables 7 and 8 . The limit of detection and limit of quantification were estimated to be $0.1157 \mathrm{mg} / \mathrm{mL}$ and $0.3821 \mathrm{mg} / \mathrm{mL}$, respectively.

3.2.4. Application of the Method to Samples. Collected samples were prepared at a concentration $\pm 0.5 \mathrm{mg} / \mathrm{mL}$. All samples analyzed contained sildenafil. Percentages of recovery are calculated and presented in Table 9. The method used allows not only identifying sildenafil in a product but also estimating the amount of sildenafil. Drug legal supply chains were all compliant in terms of drug content. These results may suggest that legal supply chains are secure. In the illicit market, both compliant and noncompliant drugs were found. Among the six (6) drug formulations from the illicit market analyzed, four (4) were noncompliant with three (3) underdosed and one (1) overdosed. Several reasons can explain these results, and more investigations are needed. 


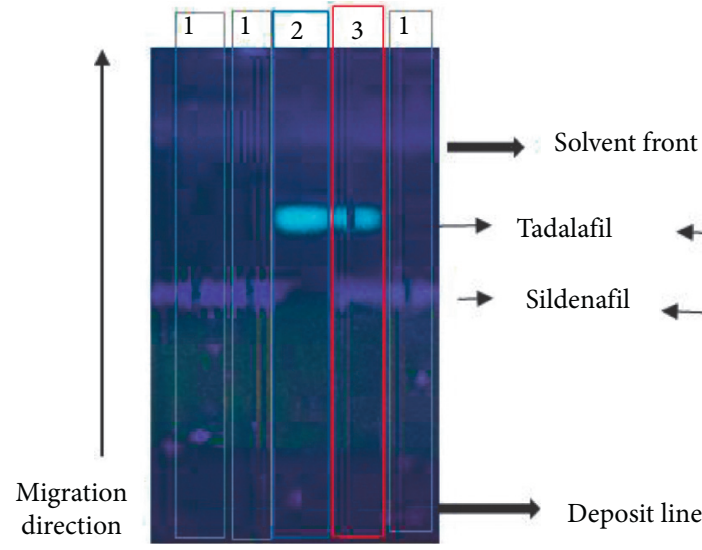

(a)

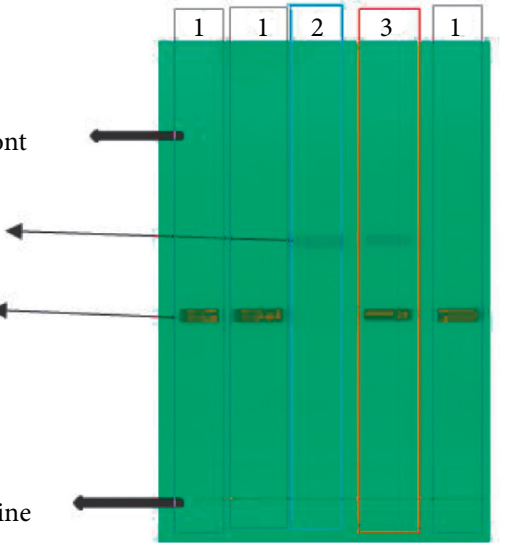

(b)
Annotations
1 Sildenafil
2 Tadalafil
3 Sildenafil + Tadalafil

Figure 2: (a) Chromatographic plate revealed under $366 \mathrm{~nm}$ light. (b) Chromatographic plate revealed under $254 \mathrm{~nm}$ light.

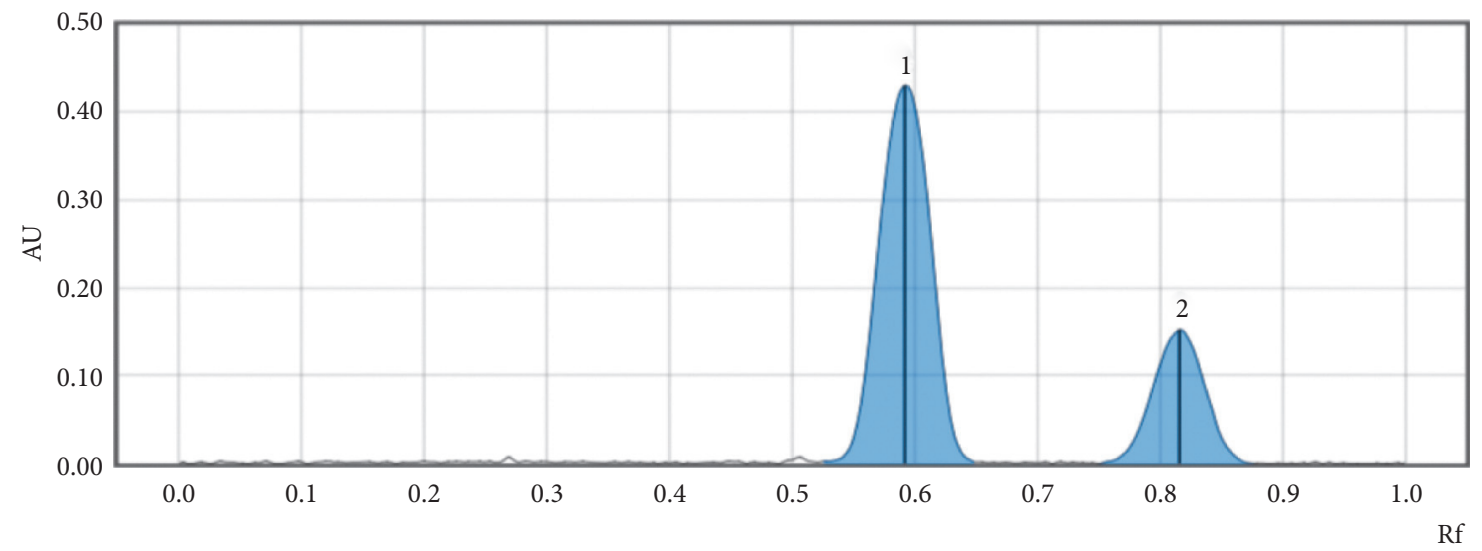

\begin{tabular}{|c|c|c|c|c|c|c|c|c|c|c|c|}
\hline \multirow{2}{*}{$\begin{array}{l}\text { Peak } \\
\#\end{array}$} & \multicolumn{2}{|c|}{ Start } & \multicolumn{3}{|c|}{ Max } & \multicolumn{2}{|c|}{ End } & \multicolumn{2}{|c|}{ Area } & \multirow{2}{*}{$\begin{array}{c}\text { Manual } \\
\text { Peak }\end{array}$} & \multirow{2}{*}{$\begin{array}{l}\text { Substance } \\
\text { Name }\end{array}$} \\
\hline & Rf & $\mathrm{H}$ & $\mathrm{Rf}$ & $\mathrm{H}$ & $\%$ & Rf & $\mathrm{H}$ & A & $\%$ & & \\
\hline 1 & 0.523 & 0.0019 & 0.592 & 0.4307 & 73.90 & 0.652 & 0.0018 & 0.02119 & 73.76 & No & \\
\hline 2 & 0.750 & 0.0002 & 0.816 & 0.1521 & 26.10 & 0.877 & 0.0002 & 0.00754 & 26.24 & No & \\
\hline
\end{tabular}

FIGURE 3: Chromatographic profile of the solution containing sildenafil and tadalafil.

TABLE 6: Equations of the overlap lines.

\begin{tabular}{ccccc}
\hline & \multicolumn{2}{c}{ Logarithmic model } & \multicolumn{2}{c}{ Polynomial model } \\
& Peak areas & Peak heights & Peak areas & Peak heights \\
\hline \multirow{3}{*}{ Model equation } & $y=1,356 x-0,0998$ & $y=1,033 x+0,0063$ & $y=0,9761 x-0,0028$ & $y=0,9183 x+0,0213$ \\
& $R^{2}=0,9856$ & $R^{2}=0,9985$ & $R^{2}=0,9968$ & $R^{2}=0,9836$ \\
& Equation (2) & Equation (3) & Equation (4) & Equation 5 \\
\hline
\end{tabular}

Quantitative analyses of most of the drugs from the illicit supply chain were above the maximum recommended dose in regard to efficacy and safety, and their use could cause several cardiovascular risks [29].

In addition to the satisfactory performance obtained (accuracy, recovery, and precision data shown above), the advantage of the present method over other reference chromatographic methods (especially HPLC) is the lower investment cost due to the relatively small volume of mobile phase used to analyze several samples at the same time on the same chromatographic plate. This also allows obtaining results very quickly. 


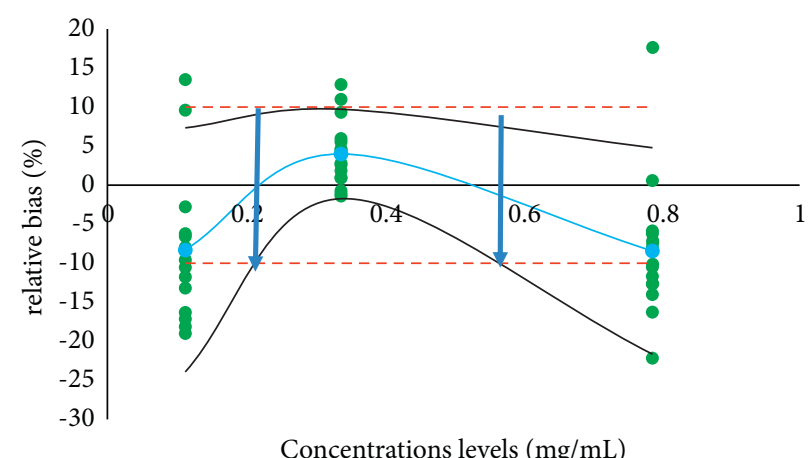

- individuals relatives bias - - - low acceptance limit

_ low tolerance limit _ _ - - high tolerance limit

- high tolerance limit $\quad-$ relative bias

FIgURE 4: Accuracy profile obtained with the polynomial function applied to peak areas.

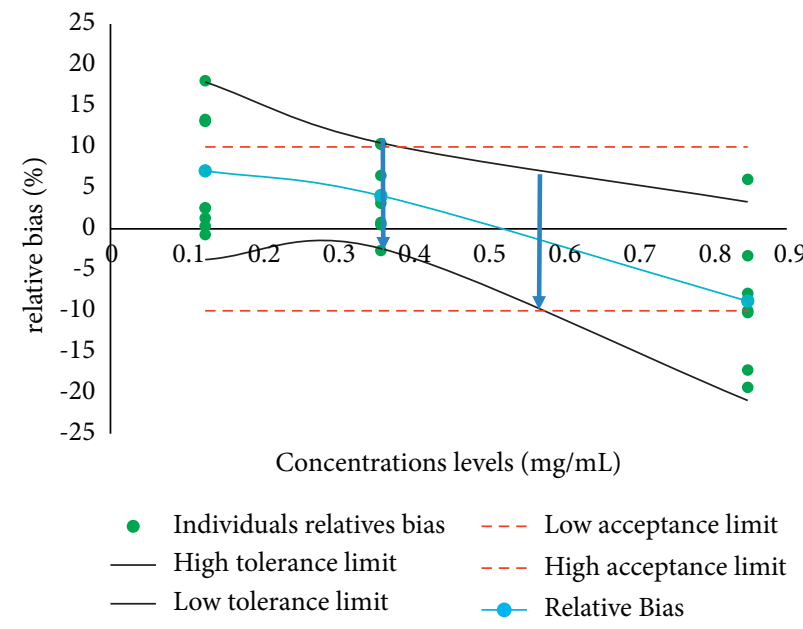

FIGURE 5: Accuracy profile obtained with the validation sample.

TABle 7: Precision data obtained with the polynomial function and the areas.

\begin{tabular}{lccc}
\hline Concentration levels $(\mathrm{mg} / \mathrm{mL})$ & 0.1125 & 0.3375 & 0.7875 \\
\hline Average found & 0.1031 & 0.3509 & 0.7213 \\
Repeatability standard deviation & 0.004779 & 0.01253 & 0.06163 \\
Intermediate fidelity standard deviation & 0.01121 & 0.01508 & 0.07148 \\
Repeatability coefficient of variation & 4.632 & 3.571 & 8.544 \\
Intermediate fidelity coefficient of variation & 10.87 & 4.296 & 9.909 \\
\hline
\end{tabular}

TABLE 8: Accuracy data obtained with the polynomial function and the areas.

\begin{tabular}{lccc}
\hline Concentration levels $(\mathrm{mg} / \mathrm{mL})$ & 0.1125 & 0.3375 & 0.7875 \\
\hline Average found by level & 0.1031 & 0.3509 & 0.7213 \\
Recovery & $91.71 \%$ & $103.99 \%$ & $91.57 \%$ \\
High tolerance limit & 49.40 & 9.911 & 5.2246 \\
Low tolerance limit & -65.98 & -1.931 & -22.08 \\
High limit of acceptability & 10 & 10 & 10 \\
Low limit of acceptability & -10 & -10 & -10 \\
\hline
\end{tabular}


TABLE 9: Determination of sildenafil content in samples.

\begin{tabular}{|c|c|c|c|c|c|}
\hline \multirow{2}{*}{ Channel type } & \multirow{2}{*}{ Drug name and dosage } & \multicolumn{3}{|c|}{ Recovery (\%) } & \multirow{2}{*}{ Compliance with Ph. Int. Specification (90-110\%) } \\
\hline & & Assay 1 & Assay 2 & Mean & \\
\hline \multirow{5}{*}{ Legal distribution chain } & Asmoforce $50 \mathrm{mg}$ & 91.25 & 96.81 & 94.03 & Compliant \\
\hline & Erekta $50 \mathrm{mg}$ & 94.82 & 95.31 & 95.06 & Compliant \\
\hline & Plaevz $50 \mathrm{mg}$ & 89.34 & 93.69 & 91.51 & Compliant \\
\hline & Cupid $50 \mathrm{mg}$ & 96.26 & 93.22 & 94.74 & Compliant \\
\hline & Erector $50 \mathrm{mg}$ & 105.9 & 107.9 & 106.9 & Compliant \\
\hline \multirow{6}{*}{ Illegal distribution chain } & Meinnah $120 \mathrm{mg}$ & 69.15 & 70.11 & 69.63 & Noncompliant \\
\hline & Yoga $100 \mathrm{mg}$ & 95.94 & 93.56 & 94.75 & Compliant \\
\hline & Kdgra $120 \mathrm{mg}$ & 66.93 & 67.55 & 67.24 & Noncompliant \\
\hline & Rygra $120 \mathrm{mg}$ & 86.81 & 102.8 & 94.80 & Compliant \\
\hline & Venegra $50 \mathrm{mg}$ & 112.6 & 112.9 & 112.7 & Noncompliant \\
\hline & Kdgra $150 \mathrm{mg}$ & 86.61 & 84.35 & 85.48 & Noncompliant \\
\hline
\end{tabular}

\section{Conclusion}

The results obtained showed that the developed HPTLC method was specific and accurate for the determination of sildenafil. It could be used therefore under the conditions described in this study to identify and quantify active substances in counterfeit drugs. This study also reveals that illicit drug markets should be of concern for regulatory authorities as they represent a life threat for the population.

\section{Data Availability}

The (mentioned or referenced) data used to support the findings of this study are included within the article and the supplementary information file.

\section{Conflicts of Interest}

The authors declare that they have no known competing financial interests or personal relationships that could have appeared to influence the work reported in this paper.

\section{Authors' Contributions}

Abdoul Karim Sakira conceptualized the study, wrote the original draft, and performed investigation. Mitéhélé Sandrine Marie Josiane Ouattara performed investigation. Moussa Yabre performed investigation and reviewed the article. Moumouni Bande performed investigation and reviewed the article. Touridomon Issa Some conceptualized and supervised the study.

\section{Acknowledgments}

The authors sincerely thank ARES-CCD (Académie de Recherche et d'Enseignement Supérieur de la Commission de Coopération au Développement) from Belgium for the financial support. This study was partly funded by ARESCCD (Académie de Recherche et d'Enseignement Supérieur de la Commission de Coopération au Développement, Belgium) through research projects.

\section{Supplementary Materials}

Supplementary Materials. The additional data refer to two Tables ( 1 and 2 ) and the equations used for the calculation of the validation parameters of the method. In Table 1 (Supplementary material), the peak areas at different wavelengths and for three concentration levels are presented. The data show that the best linearity profile was recorded at $305 \mathrm{~nm}$. In Table 2 (Supplementary material), the equations of the tested mathematical models are presented and the best results were obtained with the polynomial model applied to the peak areas. (Supplementary Materials)

\section{References}

[1] K. Dégardin, Y. Roggo, and P. Margot, "Understanding and fighting the medicine counterfeit market," Journal of Pharmaceutical and Biomedical Analysis, vol. 87, pp. 167-175, 2014.

[2] H. Rebiere, P. Guinot, D. Chauvey, and C. Brenier, "Fighting falsified medicines: the analytical approach," Journal of Pharmaceutical and Biomedical Analysis, vol. 142, pp. 286306, 2017.

[3] M. S. Rahman, N. Yoshida, H. Tsuboi et al., "The health consequences of falsified medicines-a study of the published literature," Tropical Medicine \& International Health, vol. 23, no. 12, pp. 1294-1303, 2018.

[4] G. M. L. Nayyar, A. Attaran, J. P. Clark et al., "Responding to the pandemic of falsified medicines," The American Journal of Tropical Medicine and Hygiene, vol. 92, no. 6_Suppl, pp. 113-118, 2015.

[5] A. Koczwara and J. Dressman, "Poor-quality and counterfeit drugs: a systematic assessment of prevalence and risks based on data published from 2007 to 2016," Journal of Pharmaceutical Sciences, vol. 106, no. 10, pp. 2921-2929, 2017.

[6] I. M. E. Bakker-'t Hart, D. Ohana, and B. J. Venhuis, "Current challenges in the detection and analysis of falsified medicines," Journal of Pharmaceutical and Biomedical Analysis, vol. 197, p. 113948, 2021.

[7] H. M. Ahmed, Y. S. Elshamy, W. Talaat, H. F. Labib, and T. S. Belal, "Simultaneous analysis of chlorzoxazone, diclofenac sodium and tramadol hydrochloride in presence of three potential impurities using validated HPLC-DAD and HPTLC methods," Microchemical Journal, vol. 153, Article ID 104505, 2020. 
[8] A. Shrivastava, A. Patel, and V. B. Gupta, "Stability indicating HPTLC determination of terazosin in tablet formulation," World Journal of Analytical Chemistry, vol. 1, no. 3, pp. 31-36, 2013.

[9] J. Sherma and F. Rabel, "Advances in the thin layer chromatographic analysis of counterfeit pharmaceutical products: 2008-2019," Journal of Liquid Chromatography \& Related Technologies, vol. 42, no. 11-12, pp. 367-379, 2019.

[10] T. K. T. Do, "Évaluation des performances de la chromatographie sur couche mince haute performance (HPTLC) dans l'analyse (qualitative et quantitative) des métabolites secondaires dans les extraits naturels," $\mathrm{Ph}$. D thesis, Université Côte d'Azur, Nice, France, 2016.

[11] E. Reich and A. Schibli, High-performance Thin-Layer Chromatography for the Analysis of Medicinal Plants, Thieme Medical Publishers Inc., New York, NY, USA, 2007.

[12] L. Höllein, E. Kaale, Y. H. Mwalwisi, M. H. Schulze, and U. Holzgrabe, "Routine quality control of medicines in developing countries: analytical challenges, regulatory infrastructures and the prevalence of counterfeit medicines in Tanzania," TrAC Trends in Analytical Chemistry, vol. 76, pp. 60-70, 2016.

[13] P. Bottoni and S. Caroli, "Fake pharmaceuticals: a review of current analytical approaches," Microchemical Journal, vol. 149, Article ID 104053, 2019.

[14] T. Sheshashena Reddy, A. Shiva Reddy, and P. Sita Devi, "Quantitative determination of sildenafil citrate in herbal medicinal formulations by high-performance thin-layer chromatography," Journal of Planar Chromatography-Modern TLC, vol. 19, no. 112, pp. 427-431, 2006.

[15] S. Singh, B. Prasad, A. Savaliya, R. Shah, V. Gohil, and A. Kaur, "Strategies for characterizing sildenafil, vardenafil, tadalafil and their analogues in herbal dietary supplements, and detecting counterfeit products containing these drugs," TrAC Trends in Analytical Chemistry, vol. 28, no. 1, pp. 13-28, 2009.

[16] C.-L. Kee, X. GE, V. Gilard, M. Malet-Martino, and M.-Y. Low, "A review of synthetic phosphodiesterase type 5 inhibitors (PDE-5i) found as adulterants in dietary supplements," Journal of Pharmaceutical and Biomedical Analysis, vol. 147, pp. 250-277, 2018.

[17] D. Lv, Y. Cao, L. Chen et al., "Simulation strategies for characterizing phosphodiesterase-5 inhibitors in botanical dietary supplements," Analytical Chemistry, vol. 90, no. 18, pp. 10765-10770, 2018.

[18] E. Mikami, T. Ohno, and H. Matsumoto, "Simultaneous identification/determination system for phentolamine and sildenafil as adulterants in soft drinks advertising roborant nutrition," Forensic Science International, vol. 130, no. 2-3, pp. 140-146, 2002.

[19] M. Nicoletti, "HPTLC fingerprint: a modern approach for the analytical determination of botanicals," Revista Brasileira de Farmacognosia, vol. 21, no. 5, pp. 818-823, 2011.

[20] P. Hubert, J. Nguyenhuu, B. Boulanger et al., "Harmonization of strategies for the validation of quantitative analytical proceduresA SFSTP proposal-part I," Journal of Pharmaceutical and Biomedical Analysis, vol. 36, no. 3, pp. 579-586, 2004.

[21] P. Hubert, J.-J. Nguyen-Huu, B. Boulanger et al., "Harmonization of strategies for the validation of quantitative analytical procedures," Journal of Pharmaceutical and Biomedical Analysis, vol. 45, no. 1, pp. 70-81, 2007.

[22] P. Hubert, J.-J. Nguyen-Huu, B. Boulanger et al., "Harmonization of strategies for the validation of quantitative analytical procedures," Journal of Pharmaceutical and Biomedical Analysis, vol. 45, no. 1, pp. 82-96, 2007.

[23] M. Feinberg, pp. 27-44, 2010, Mise en œuvre du profil d'exactitude. Validation des méthodes d'analyse quantitative par le profil d'exactitude [Internet].

[24] S. Nyiredy, "Planar chromatographic method development using the PRISMA optimization system and flow charts," Journal of Chromatographic Science, vol. 40, no. 10, pp. 553-563, 2002.

[25] EDQM, European Pharmacopoeia, EDQM, Strasbourg, France, 9th edition, 2016.

[26] ICH Guidelines, Validation of Analytical Procedures: Text and Methodology Q2 (R1), International Conference on Harmonization, Geneva, Switzerland, 2005.

[27] E. Abourashed, M. Abdel-Kader, and A.-A. Habib, "HPTLC determination of sildenafil in pharmaceutical products and aphrodisiac herbal preparations," Journal of Planar Chromatography-Modern TLC, vol. 18, no. 105, pp. 372-376, 2005.

[28] P.-T. Wilrich, "The determination of precision of qualitative measurement methods by interlaboratory experiments," Accreditation and Quality Assurance, vol. 15, no. 8, pp. 439-444, 2010.

[29] E. P. Krenzelok and E. Krenzelok, "Sildenafil: clinical toxicology profile," Journal of Toxicology: Clinical Toxicology, vol. 38, no. 6, pp. 645-651, 2000. 